\title{
Effect of the pH in the Growth of Benzotriazole Model Layers at Realistic Environmental Conditions.
}

Authors: Andrea Mirarco, ${ }^{\mathrm{a}, \mathrm{b}}$ Stephen M. Francis ${ }^{\mathrm{a}}$, Christopher J. Baddeley ${ }^{\mathrm{a}}$, Antonella Glisenti ${ }^{\mathrm{b}}$, Federico Grillo $\mathrm{a}^{\mathrm{a} *}$

Affiliations: ${ }^{\text {a }}$ EaStCHEM - School of Chemistry, University of St. Andrews, St. Andrews, KY16 9ST, United Kingdom; ${ }^{b}$ Department of Chemical Sciences, University of Padova, Via F. Marzolo, $1-35131$ Padova - Italy

Corresponding Author(s):*federico.grillo@st-andrews.ac.uk

\begin{abstract}
The growth of benzotriazole (BTAH) via solution deposition onto copper monolayers prepared via underpotential deposition (UPD) on $\mathrm{Au}(111) /$ mica substrates has been investigated using X-ray photoelectron spectroscopy (XPS) and ambient scanning tunnelling microscopy (STM) as a function of solution $\mathrm{pH}$ and immersion time. Adsorbed species have been found sensitive to the solution $\mathrm{pH}$ with a higher benzotriazole surface concentration following deposition from an acidic environment. Although the layers prepared at different $\mathrm{pH}$ are chemically different, as highlighted by XPS, similar morphologies are recorded via STM. These results are critically discussed in the light of some of the adsorption models previously reported.
\end{abstract}

Keywords: copper; oxidation; passive films; XPS; STM

\section{Introduction}

Copper and its alloys are widely used in a variety of applications, from electrical wiring and plumbing, to electronic and microelectronics, to ornaments, due to desirable properties such as high thermal and electrical conductivity, ductility, malleability, and corrosion resistance [1]. Copper behaves like a noble metal because its surface is passivated by a naturally protective film [2], mainly consisting of cuprous oxide $\left(\mathrm{Cu}_{2} \mathrm{O}\right)$, which can protect the copper surface from corrosion. However, when copper is exposed to environments exhibiting harsh conditions, it may be susceptible to corrosive phenomena. In aqueous environment, copper corrosion has often been associated with the presence of chloride ions alone, or in combination with other reactive molecular species, to the extent that it cannot be completely prevented. One useful approach to minimize corrosion is to use corrosion inhibitors, additives which, in low concentration, decrease the deterioration of 
the surface layers. Benzotriazole (BTAH, figure 1) coatings have long been established as an efficient method of passivating copper surfaces [3-6].

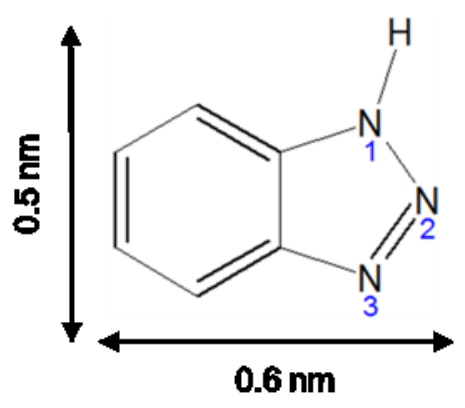

Figure 1. Benzotriazole (BTAH) molecular structure with approximate molecular dimensions.

Since the early work of Cotton et al. [7, 8] there has been ever growing interest in understanding the mechanism of corrosion inhibition and therefore in the interaction of BTAH with both oxide-free [7-35] and oxide-covered [7-10, 13-18, 28, 32], copper surfaces. However, the origin of the particular efficacy of $\mathrm{BTAH}$, in term of its detailed bonding, is not really explained and controversial data and interpretation are reported [4-6]. BTAH has been proposed to interact with the copper substrate resulting in the formation of a copper metal complex through the nitrogen atoms [7-8, 16-18, 32] capable of generating a polymer chain [9, 19, 22, 26-28, 31-32]. BTAH was also observed to adopt different orientation on copper surfaces, i.e. adopting an upright/tilted [10, 13, 23-25, 32-36] or flat orientation [14-15, 32-34, 36, 37 on $\mathrm{Au}(111)]$ with respect to the surface or a mix of these orientations [14-15, 33-34]. The majority of previous studies focus on ideal model systems such as clean copper surfaces, or theoretical calculations. In attempts to simulate real application conditions, several studies were undertaken in a liquid acidic environment on copper single crystals [15-17]. Studies conducted at real conditions usually focus on bulk copper samples, the surface of which is considered, evaluating the influence of the $\mathrm{pH}$ in aqueous solution [9, 11, 26-27, 30,38], synergistic effects due to the presence of other additives [30, 39], static and flow conditions [29]. Nevertheless, the investigation of the interaction of benzotriazole with real or realistic copper surfaces is made more complex both because of the multiplicity of the possible interactions occurring within the system studied, and by the difficulty of performing surface science measurements under realistic conditions.

The aim of this research is to study the interaction between benzotriazole and copper containing substrates exposed to realistic operating conditions, at room temperature. X-ray Photoelectron Spectroscopy (XPS) and ambient Scanning Tunnelling Microscopy (STM) measurements were carried out upon immersion of the samples in benzotriazole containing solutions to gain a chemical and morphological characterisation of the system. The samples consisted of copper monolayers prepared via underpotential deposition on $\mathrm{Au}(111) /$ mica substrates. The use of well-defined copper monolayers allows one to obtain information on the benzotriazole-copper interface, as, by limiting the interaction of BTAH with a single layer of copper atoms, 
3D film growth is minimised, and BTAH interaction with the sample surface layer is rendered more evident. As a result, the gap between model studies, undertaken under ideal conditions, and realistic studies, performed at realistic conditions, can be bridged. The $\mathrm{Cu}-\mathrm{BTAH}$ interaction has been considered as a function of exposure parameters such as solution $\mathrm{pH}$ and immersion time.

\section{Materials and Methods}

Samples consisted of copper monolayers prepared on $\mathrm{Au}(111) /$ mica substrates (300 nm epitaxial, Georg Albert PVD, Silz, Germany). Substrates annealed using natural gas flame prior to use and copper overlayers prepared by underpotential deposition $(\mathrm{UPD})$, to yield a $(5 \times 5)$ chlorine terminated copper monolayer (set potential of 0.2 V) [40, 41, 42]. UPD layers were produced in a hydrochloric acid solution (10\%) containing $50 \mathrm{mM} \mathrm{CuSO}_{4}$ (Sigma-Aldrich, 99.999\%) and $10 \mathrm{mM} \mathrm{KCl} \mathrm{(Fluka,} \mathrm{\geq} \mathrm{99.5 \% ).} \mathrm{A} \mathrm{cyclic} \mathrm{voltammogram} \mathrm{was}$ recorded to ascertain the quality of the Au/mica substrate prior to perform the metal deposition (a typical cyclic voltammogram is shown in SI1). Inhibitor stock solutions were prepared by dissolving $10 \mathrm{mmol}$ (1.192 g) of BTAH (Sigma-Aldrich, 99\%) in $1000 \mathrm{ml}$ of $\mathrm{NaCl}$ solution $0.5 \mathrm{M}$, at room temperature, under magnetic stirring; $\mathrm{HCl}(1 \%)$ and $\mathrm{NaOH}(1 \%)$ were used to obtain the desired $\mathrm{pH}$.

XPS measurements were performed on a Scienta ESCA 300 spectrometer, using a conventional Al anode $(\mathrm{K} \alpha 1486.6 \mathrm{eV}, 10 \mathrm{kV}, 20 \mathrm{~mA})$. The detection system consisted of a large hemispherical analyser coupled to a multichannel plate/video camera. The instrument was calibrated on a daily basis to the $\mathrm{Au} 4 \mathrm{f}$ and $\mathrm{Ag} 3 \mathrm{~d}$ photoelectron lines. The binding energy scale was referenced to the $A u 4 f_{7 / 2}$ core level peak at $84.0 \mathrm{eV}$. All spectra were analysed using the CasaXPS [43] software package.

STM topographs were collected on a nanoscope Pico STM, in constant current mode, at ambient conditions, using mechanically cut Pt/Ir tips (80:20 wire, Advent Research Materials Ltd., $0.25 \mathrm{~mm}$ diameter). Images were processed using the WSxM software package [44].

Substrates were immersed in the BTAH containing solutions for the necessary time, in static conditions and at room temperature; after removal from the solutions and prior to XPS and STM analysis, substrates were rinsed in deionised water and dried in a nitrogen flow.

\section{Results}

\subsection{XPS measurements}

Figure 2a shows the $\mathrm{Cu} 2 \mathrm{p}_{3 / 2}$ region before and after immersion of $\mathrm{Cu}(\mathrm{UPD}) / \mathrm{Au}(111) /$ mica layers into BTAH solutions at pH 6 for different lengths of time. After the copper layer is prepared and before immersion, the $\mathrm{Cu} 2 \mathrm{p}_{3 / 2}$ region can be fitted with a peak having maximum at $932.3 \mathrm{eV}$, with a small shoulder at $935.5 \mathrm{eV}$; both peaks have a FWHM of $1.87 \mathrm{eV}$ (see the peak fitting for the as prepared layers in table S1 and SI2). The $\mathrm{Cu} 2 \mathrm{p}_{3 / 2}$ region changes after immersion in the BTAH solution at $\mathrm{pH} 6$ for 30 minutes. The total area 
decreases, the peak maximum shifts to $932.7 \mathrm{eV}$, a new peak appears at $935.6 \mathrm{eV}$, the FWHM increases to $1.92 \mathrm{eV}$ and a raised background, due to satellite features, is seen between $940 \mathrm{eV}$ and $948 \mathrm{eV}$. After longer immersion times, the maximum of the $\mathrm{Cu} 2 \mathrm{p}_{3 / 2}$ shifts to slightly lower binding energy values, the overall peak areas, including the satellite regions, decrease in intensity. Figure $2 b$ shows the $\mathrm{Cu}_{3} \mathrm{M}_{45} \mathrm{M}_{45}$ (referred to as LMM for simplicity) Auger transition recorded after preparing the copper UPD layer and after immersion into the BTAH solution at $\mathrm{pH} 6$ for different times. It has been reported that the copper LMM Auger transition is comprised of four peaks, the most intense one at a kinetic energy of ca. $918.4 \mathrm{eV}$; with other transitions at $921.1 \mathrm{eV}, 916.0 \mathrm{eV}$ and $914.0 \mathrm{eV}$ [45]; the Auger spectra from a sputtered copper single crystal is reported in SI3 for comparison. Before exposure to BTAH, the $\mathrm{Cu}$ LMM main peak is recorded at $918.1 \mathrm{eV}$, with shoulders at $920.5 \mathrm{eV}$ and a raised background at lower kinetic energy (see table S1.) The shape of the transition is very similar to that recorded for $\mathrm{CuI}$ (SI3), where copper is in the +1 oxidation state. After exposure to the BTAH solution, the overall intensity of the transition decreases, the maximum of intensity shifts to a kinetic energy of $917.9 \mathrm{eV}$ and a new feature appears at ca. $914.8 \mathrm{eV}$. Upon further exposure, the two observed peaks keep decreasing in intensity with the peak at $917.9 \mathrm{eV}$ initially decreasing faster than that at $914.8 \mathrm{eV}$.
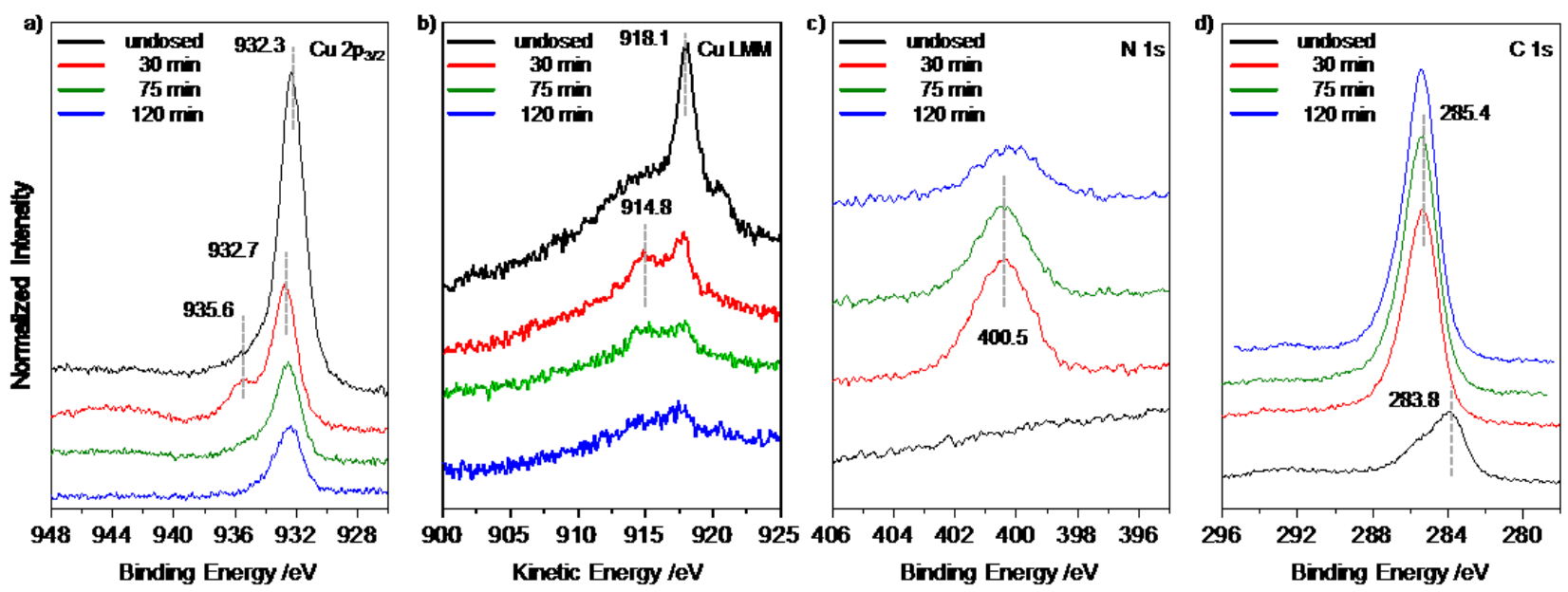

Figure 2. a) $\mathrm{Cu} 2 \mathrm{p}_{3 / 2} \mathrm{XP}$ spectra before and after immersion in BTAH solution at $\mathrm{pH} 6$ for increasing times; b) corresponding $\mathrm{Cu}$ LMM Auger transitions, c) N 1s and d) C 1s spectra.

Figure $2 \mathrm{c}$ and $2 \mathrm{~d}$ show the $\mathrm{N} 1 \mathrm{~s}$ and $\mathrm{C} 1 \mathrm{~s}$ regions (see SI $2 \mathrm{~b}$ and $\mathrm{c}$, where the peak fitting is reported). Before exposing to BTAH, the $\mathrm{N}$ 1s region shows a flat line; after immersing into the solution, a single $\mathrm{N}$ 1s peak is recorded at $400.5 \mathrm{eV}$, with a FWHM of $2.22 \mathrm{eV}$. The peak becomes a little broader and less intense with increasing immersion times. Benzotriazole is the only source of nitrogen in the system. The $\mathrm{C} 1 \mathrm{~s}$ region shows a peak with maximum at $283.8 \mathrm{eV}(1.77 \mathrm{eV}$ FWHM) and some other additional components before immersion. After immersion the maximum of the $\mathrm{C} 1 \mathrm{~s}$ shifts to $285.4 \mathrm{eV}$, the FWHM increases to $2.10 \mathrm{eV}$. The peak increases in intensity and a raised background with maximum at $292.4 \mathrm{eV}$ develops with increasing immersion times. Only a small amount of oxygen is present before immersion (S2 2d peak maximum at 
$532.1 \mathrm{eV}, 1.85 \mathrm{eV}$ FWHM); after immersion the $\mathrm{O} 1 \mathrm{~s}$ peak increases with the immersion time, maximum at $533.5 \mathrm{eV}$, with a shoulder at $536.7 \mathrm{eV}$, which progressively decreases in intensity; ca. $2.5 \mathrm{eV}$ FWHM. Before exposure to the BTAH solutions, a Cl 2p at $197.5 \mathrm{eV}$ was seen (fittings in SI 2e). This is due to the chloride termination over the copper layer produced during the under potential deposition process [40, 41, 42]. The peak can be resolved into the $3 / 2$ and $1 / 2$ components and has a narrow FWHM $(1.89 \mathrm{eV})$. A shoulder to higher binding energy (with a possible $2 \mathrm{p}_{3 / 2}$ peak at ca. $201 \mathrm{eV}$ ), might indicate a small amount of an oxychloride species [46]. Upon immersion in the BTAH solution, after the first 30 minutes the total signal seems to increase a little, the FWHM increases $(2.43 \mathrm{eV})$; both the total signal and FWHM decrease following longer immersion. In particular, the tail at higher binding energy decreases at a faster rate.

Traces of Na were seen after immersion, as those ions were present in the BTAH stock solution.

As shown in figure $3 \mathrm{a}$, the $\mathrm{Cu} 2 \mathrm{p}_{3 / 2}$ XP spectra after immersion in the BTAH solution at pH 5 show very similar features to those observed after immersions in the $\mathrm{pH} 6$ solutions (peak fitting is reported in SI 4a). The peak maximum is recorded at $932.7 \mathrm{eV}(2.32 \mathrm{eV}$ FWHM), with a shoulder at $935.7 \mathrm{eV}$ and a raised background between $940 \mathrm{eV}$ and $948 \mathrm{eV}$ due to satellite features. With increased exposure, the intensity of all peaks decreases. However, the Cu LMM region shows some differences (figure 3b). After immersion, two peaks are recorded at kinetic energies of $917.8 \mathrm{eV}$ and $915.2 \mathrm{eV}$. The peak at $915.2 \mathrm{eV}$ has a larger area than that at $917.8 \mathrm{eV}$ after the initial exposure. With increasing exposures, the Auger transition is attenuated with the peak at $915.2 \mathrm{eV}$ decreasing faster, similarly to what observed after immersion at $\mathrm{pH}$ 6. Likewise, after immersion, an $\mathrm{N} 1 \mathrm{~s}$ peak with maximum at $400.5 \mathrm{eV}$ (SI 4b), a C 1s with maximum at $285.4 \mathrm{eV}$ (SI 4c) and an $\mathrm{O} 1 \mathrm{~s}$ peak with maximum at $533.5 \mathrm{eV}$ (SI 4d) were observed. Both the $\mathrm{N}$ 1s and $\mathrm{C}$ 1s peak decreased in intensity with longer immersion times, whilst the O 1s increased. Similarly to the observed behaviour after immersion at $\mathrm{pH} 6$, the $\mathrm{Cl} 2 \mathrm{p}$ increases after $30 \mathrm{~min}$ and then decreases.
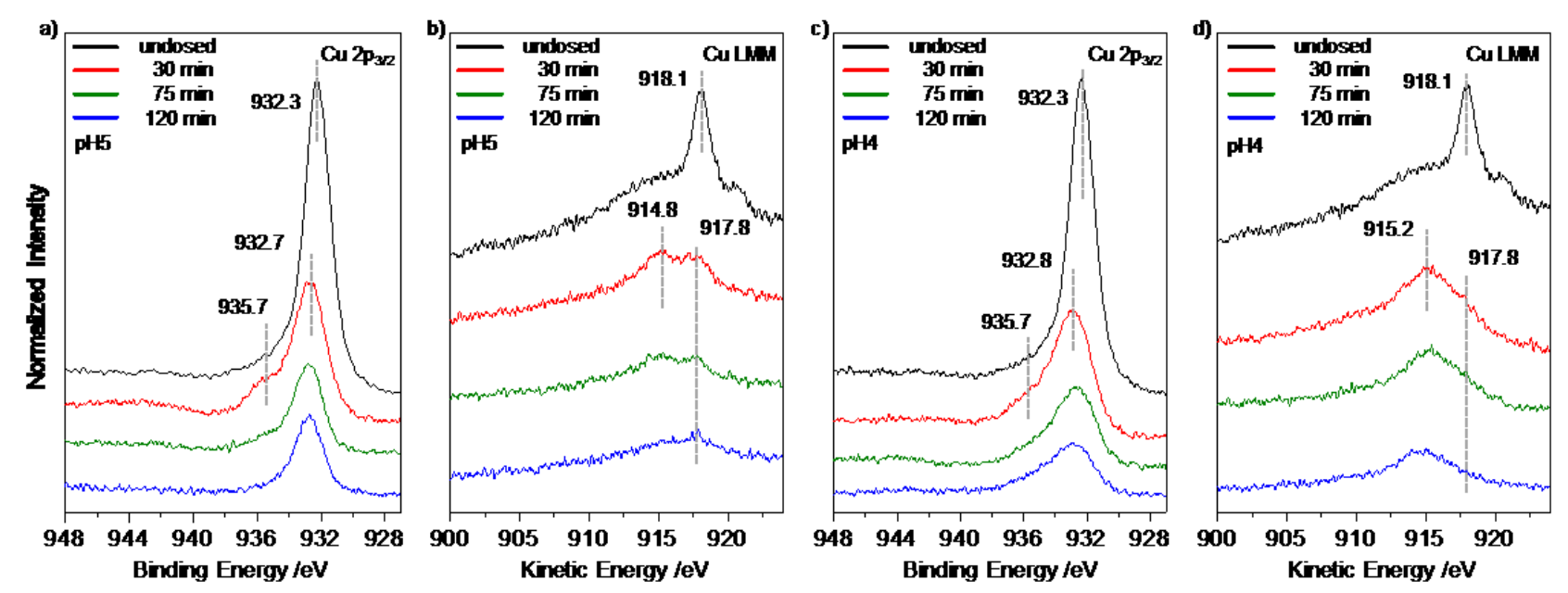

Figure 3. a) $\mathrm{Cu} 2 \mathrm{p}_{3 / 2} \mathrm{XP}$ spectra before and after immersion in BTAH solution at $\mathrm{pH} 5$ for increasing times; b) corresponding $\mathrm{Cu}$ LMM Auger transitions spectra; c) $\mathrm{Cu} 2 \mathrm{p}_{3 / 2}$ XP spectra before and after immersion in BTAH solution at $\mathrm{pH} 4$ for increasing times; d) corresponding $\mathrm{Cu} \mathrm{LMM}$ Auger transitions spectra. 
Figures $3 \mathrm{c}$ and $3 \mathrm{~d}$ show the $\mathrm{Cu} 2 \mathrm{p}_{3 / 2} \mathrm{XP}$ and $\mathrm{Cu}$ LMM Auger transition spectra recorded after immersing the $\mathrm{Cu}(\mathrm{UPD}) / \mathrm{Au}(111) /$ mica substrates into the BTAH solution at $\mathrm{pH} 4$ for increasing times (peak fittings are reported in SI 5a). After the initial 30 minutes exposure, the $\mathrm{Cu} 2 \mathrm{p}_{3 / 2}$ shows a maximum at $932.8 \mathrm{eV}$, with a shoulder at $935.7 \mathrm{eV}$, and the peak's FWHM increases to $2.63 \mathrm{eV}$. A weak satellite structure is still present. With increasing exposure to BTAH, both peaks are attenuated and their FWHM increase. The Cu LMM region shows a different behaviour yet again. A peak with a large FWHM is recorded at a kinetic energy of $915.2 \mathrm{eV}$ with a raised background at the lower kinetic energy side. The peak recorded at $917.8 \mathrm{eV}$ is now very weak. With increasing exposures, the Auger transition is attenuated with the peak at $917.8 \mathrm{eV}$ decreasing faster, and the shoulder at $914 \mathrm{eV}$ becoming more evident. After immersion, the $\mathrm{N} 1 \mathrm{~s}$ peak shows a maximum at $400.6 \mathrm{eV}$, with a shoulder at $403.1 \mathrm{eV}$ (SI 5b) and a C 1s with maximum at $285.3 \mathrm{eV}$ (SI 5c). The $\mathrm{O} 1 \mathrm{~s}$ peak shows a maximum at $532 \mathrm{eV}$ (SI $5 \mathrm{~d}$ ). The $\mathrm{N} 1 \mathrm{~s}$ decreased in intensity with longer immersion times, whilst the $\mathrm{C} 1 \mathrm{~s}$ stayed approximately constant and the $\mathrm{O} 1 \mathrm{~s}$ increased in intensity. The $\mathrm{Cl} 2 \mathrm{p}$ decreases in intensity, this time however, the tail at high binding energy is more persistent, but the signal decreases faster than for the other solutions.

\subsection{STM measurements}

Figure 4a recorded after immersing a sample in the BTAH solution at $\mathrm{pH} 6$ for 75 minutes is a typical example of surface topography. BTAH molecular features appear as elongated protrusions and organise in chain-like structures which follow essentially three propagation directions related by a $120^{\circ}$ rotation. The peak to peak distance between the elements composing a chain-like feature is $0.35 \pm 0.02 \mathrm{~nm}$. This value implies that adsorbed molecules are to some extent in registry with the underlying $(5 \times 5) \mathrm{Cl}$ terminated $\mathrm{Cu}$ layer which is reported to have an average copper adatom spacing of $0.36 \mathrm{~nm}$ [40]. When compared with the dimensions of gas phase BTAH (figure 1), this suggests that the molecules are oriented upright or perhaps approximately perpendicular with respect to the surface. The distance between two adjacent BTA units may indicate the possibility of $\pi-\pi$ interactions between the aromatic systems [47]. Although the overall propagation occurs along three rotationally equivalent surface directions, chain-like features appear to deviate from a straight line, and exhibit irregular widths.

Statistical analysis undertaken at the different immersion times, normalised to a $10 \times 10 \mathrm{~nm}^{2}$ area, shows a tendency for BTAH features to agglomerate in short ensembles, composed of 1 to 3 units (figure $4 \mathrm{~b}$ ). However, the increase in exposure times seems to favour the presence of features comprised of a higher number of elements; in fact, chains with fewer units are always more numerous but, with increasing immersion time, the number of chains exhibiting longer dimensions increase. As expected, the surface coverage increases with increasing the immersion time, going from ca. $38 \%$ at 30 minutes to ca. $66 \%$ at 75 minutes, to ca. $89 \%$ at 120 minutes. 
STM images collected after immersing the samples in BTAH solutions at $\mathrm{pH} 5$ and $\mathrm{pH} 4$ show essentially the same topographic features and behaviour with increasing exposure times. Additional images are reported in SI6.
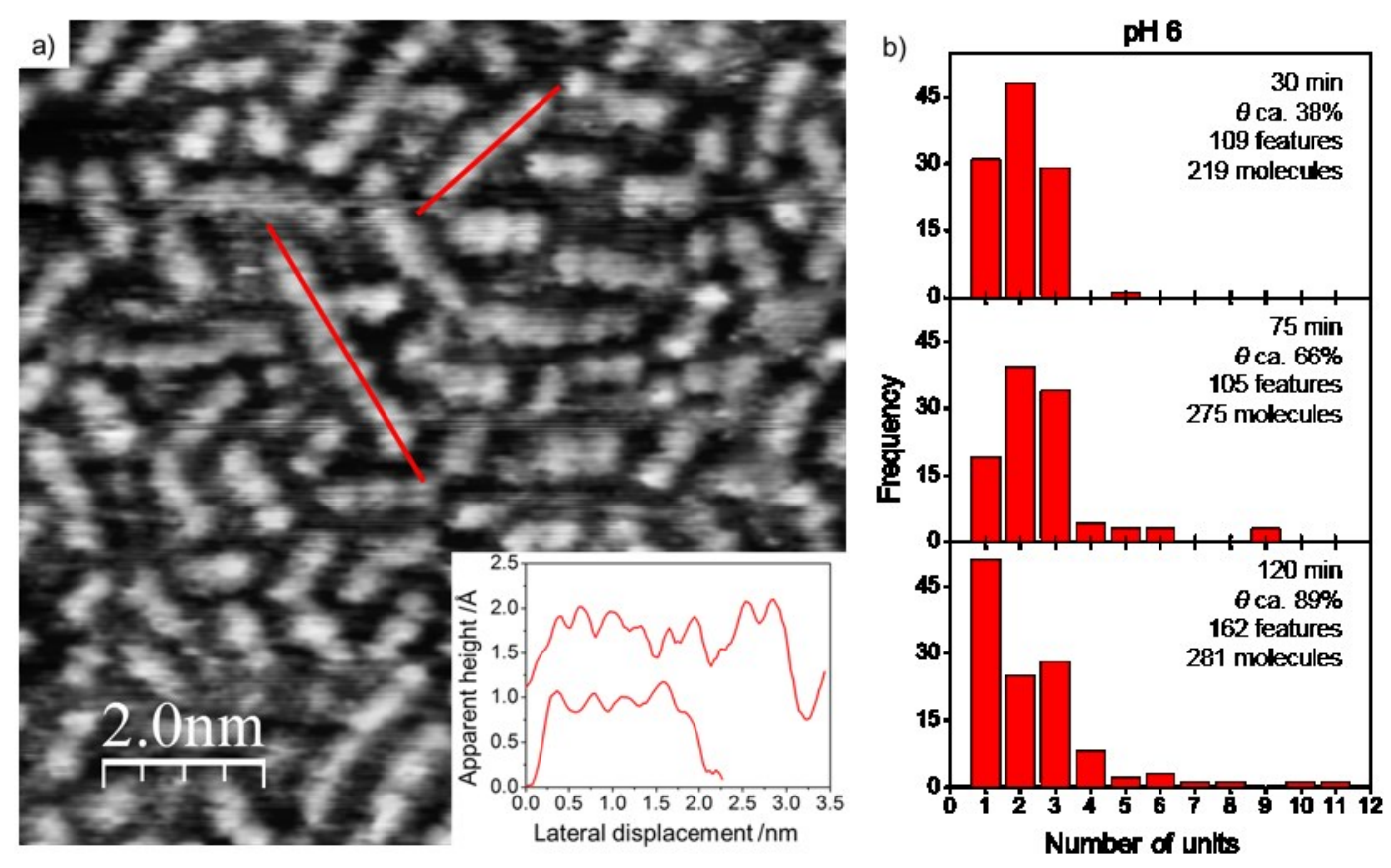

Figure 4. a) STM topography of a $(5 \times 5)$ Cl-terminated $(1 \times 1) \mathrm{Cu}(\mathrm{UPD}) / \mathrm{Au}(111) /$ mica sample immersed into a BTAH solution at $\mathrm{pH} 6$ for 75 minutes. $10 \times 10 \mathrm{~nm}^{2}, 0.2 \mathrm{~V}, 0.075 \mathrm{nA}$. In the inset, line profiles as shown in picture. b) Statistics on length of chains at $\mathrm{pH} 6$, normalized to a $100 \mathrm{~nm}^{2}$ area.

\section{Discussion}

The choice of preparing copper monolayers by underpotential deposition (UPD) is motivated by the necessity to control the amount of copper and evaluate its oxidation state reliably. In fact, through UPD, copper monolayers can be prepared and have been demonstrated to have a well-defined geometry with no intermixing between the two metals [40, 41, 42]. Another advantage of these preparations is the absence in the $\mathrm{Cu} 2 \mathrm{p} \mathrm{XP}$ and LMM regions of a contribution due to the bulk, which are indeed present when using single crystals, or bulk specimens. The presence of copper is confirmed by a $\mathrm{Cu} 2 \mathrm{p}_{3 / 2} \mathrm{XP}$ peak at $932.3 \mathrm{eV}$ and fine structure of the Auger $\mathrm{L}_{3} \mathrm{M}_{45} \mathrm{M}_{45}$ transition. For similar preparations binding energies of ca. 932.5 $\mathrm{eV}$ [48] and $931.1 \mathrm{eV}$ [49] are reported. Following such preparation method, the copper layer is capped by a layer of chloride atoms, therefore copper is expected to be oxidised. As a reference, $\mathrm{Cu} 2 \mathrm{p}_{3 / 2}$ binding energies and $\mathrm{Cu}$ LMM kinetic energies for copper and relevant copper chlorides and oxides are reported in Table 1. The most intense component of the Auger LMM transition is recorded at a kinetic energy of $918.1 \mathrm{eV}$, a value much closer to that of $\mathrm{Cu}(0)$, than of $\mathrm{Cu}(\mathrm{I})$. However, the line-shape generated by bulk $\mathrm{CuCl}$ is very 
similar to that of metallic copper, albeit much less intense and broadened $[50,51]$. A Cl $2 p_{3 / 2}$ peak at 197.3 $\mathrm{eV}$ confirms the presence of chlorine negatively charged. This value is much lower than those previously reported for chlorine in bulk $\mathrm{CuCl}$ and $\mathrm{CuCl}_{2}$, as evidenced by the comparison with the binding energy values reported in Table 1, indicating that chlorine is a surface species, other than negatively charged. After preparation copper atoms are essentially in the +1 oxidation state and are capped by a layer of chloride atoms. $\mathrm{A} \mathrm{Cu}: \mathrm{Cl}$ ratio of ca. 1:2.2 is estimated, corresponding to a $\mathrm{CuCl} \cdot \mathrm{Cl}$ surface species. The attenuation of the copper signal may be explained by the fact that copper atoms are covered by chlorine species.

The fine structure of the $\mathrm{Cu}$ LMM Auger transition is different in shape, less resolved and broader than that for exhibited by bulk copper. The geometry of the layers, which is not directly accessible through XPS measurements alone, is discussed elsewhere [42]; however, the superposition of these layers is enough to create several slightly different copper chemical environments, which result in a broader distribution of kinetic energies for the Auger electrons, reflecting in an increased FWHM for the whole LMM transition.

Upon immersion of the samples in the BTAH containing solutions, the $\mathrm{Cu} 2 \mathrm{p}_{3 / 2}$ shows a shift towards higher binding energy, $932.7 \mathrm{eV}$; this shift alone may be not enough to warrant a change in the copper oxidation state from +1 to +2 , albeit it may indicate a change in the copper chemical environment. $\mathrm{A} \mathrm{Cu} 2 \mathrm{p}_{3 / 2}$ component developed at higher $\mathrm{BE}$ than for the original copper substrate, $938.4 \mathrm{eV}$, was previously attributed to the $\mathrm{Cu}(\mathrm{I})$-BTA polymeric complex $[17,59,60]$. However, in this work, the development of a shoulder at ca. $935.7 \mathrm{eV}$ and of a satellite structure at ca. $9 \mathrm{eV}$ higher binding energy is indicative of the presence of some copper in the +2 oxidation state $[61,62]$.

\begin{tabular}{|c|c|c|c|c|c|c|}
\hline & $\begin{array}{l}\mathrm{Cu} 2 \mathrm{p}_{3 / 2} \\
\mathrm{BE} / \mathrm{eV}\end{array}$ & $\begin{array}{c}\mathrm{LMM} \\
\mathrm{KE} / \mathrm{eV}\end{array}$ & $\begin{array}{l}\alpha^{\prime} \\
/ \mathrm{eV}\end{array}$ & $\begin{array}{c}\mathrm{O} 1 \mathrm{~s} \\
\mathrm{BE} / \mathrm{eV}\end{array}$ & $\begin{array}{l}\mathrm{Cl} 2 \mathrm{p}_{3 / 2} \\
\mathrm{BE} / \mathrm{eV}\end{array}$ & Ref. \\
\hline $\mathrm{Cu}$ & $\sim 932.5$ & & & & & 48 \\
\hline UPD & 931.1 & & & & & 49 \\
\hline \multirow{3}{*}{$\mathrm{CuCl}$} & 931.8 & & & & 199.5 & 50 \\
\hline & 932.2 & 915.6 & 1847.8 & & & 52 \\
\hline & 932.4 & 915.5 & 1847.9 & & 199.7 & 54 \\
\hline \multirow{4}{*}{$\mathrm{CuCl}_{2}$} & 934.6 & & & & 199.8 & 51 \\
\hline & 933.8 & 915.5 & 1850.1 & & & 52 \\
\hline & 933.8 & 916.6 & 1850.4 & & 198.0 & 53 \\
\hline & 933.9 & & & & 199.2 & 53 \\
\hline \multirow{5}{*}{$\mathrm{Cu}$} & 9324 & 919.0 & 1851.4 & & & 52 \\
\hline & $\begin{array}{l}932.4 \\
9329\end{array}$ & 918.3 & 1851.2 & & & 54 \\
\hline & $\begin{array}{l}932.9 \\
9326\end{array}$ & 918.0 & 1850.6 & & & 55 \\
\hline & $\begin{array}{l}932.6 \\
9326\end{array}$ & 918.4 & 1851.0 & & & 56 \\
\hline & & 918.5 & & & & 57 \\
\hline \multirow{5}{*}{$\mathrm{Cu}_{2} \mathrm{O}$} & 932.0 & 917.1 & 1849.1 & & & 52 \\
\hline & 932.5 & 915.8 & 1848.3 & 530.8 & & 55 \\
\hline & 932.4 & 916.5 & 1848.9 & & & 56 \\
\hline & 933.3 & 916.3 & 1849.6 & & & 57 \\
\hline & 932.3 & 916.8 & 1849.1 & 530.2 & & 58 \\
\hline \multirow{7}{*}{$\mathrm{CuO}$} & 933.6 & & & & & 52 \\
\hline & 933.6 & 917.9 & 1851.5 & 529.4 & & 53 \\
\hline & 932.7 & 917.1 & 1850.7 & 529.8 & & 53 \\
\hline & 934.0 & 918.0 & 1850.7 & 529.9 & & 55 \\
\hline & 933.6 & 917.1 & 1851.1 & & & 56 \\
\hline & 933.6 & 917.8 & 1851.4 & 530.3 & & 57 \\
\hline & 933.9 & & & 529.7 & & 58 \\
\hline
\end{tabular}

Table 1. Binding energy, kinetic energy and Auger parameters values for copper and selected compounds. 
Therefore a mix of $\mathrm{Cu}(\mathrm{I})$ and $\mathrm{Cu}(\mathrm{II})$ is now present, with the majority still being in favour of $\mathrm{Cu}(\mathrm{I})$. This is observed consistently for the initial exposure at every $\mathrm{pH}$; with increasing immersion times both the shoulder at higher binding energy and the satellite structure tend to be less pronounced. The LMM Auger transition shows the peak related to copper in a chloridic environment decreasing in intensity and a new feature appearing at $914.8 \mathrm{eV}$. This second feature was previously attributed to a $\mathrm{Cu}(\mathrm{I}) \mathrm{BTA}$ compound $[63,64,65]$. From the data reported in Table 1, for bulk compounds, the $\mathrm{Cu}$ LMM for $\mathrm{Cu}(\mathrm{I})$ is expected at an average kinetic energy of $916.5 \mathrm{eV}$ for $\mathrm{Cu}_{2} \mathrm{O}$ and $915.5 \mathrm{eV}$ for $\mathrm{CuCl}$, whereas at a kinetic energy of ca. $917.6 \mathrm{eV}$ for $\mathrm{CuO}$ and $916.0 \mathrm{eV}$ for $\mathrm{CuCl}_{2}$ for $\mathrm{Cu}$ (II). Thus, other than to the oxidation state, the $\mathrm{LMM}$ seem to be dependent upon the chemical environment of the copper atoms. A clear peak indicating the presence of $\mathrm{Cu}$ (II) could not be observed in the LMM region. Thus, considering both the $\mathrm{Cu} 2 \mathrm{p}_{3 / 2}$ and $\mathrm{Cu}$ LMM regions, after the initial immersions in the BTAH solution, the vast majority of copper atoms are essentially still in the +1 oxidation state, even though some $\mathrm{Cu}$ (II) is also present.

As immersion time increases, especially for $\mathrm{pH} 6$ and $\mathrm{pH}$, the amount of $\mathrm{Cu}(\mathrm{II})$ decreases until the only detectable copper oxidation state remaining on the surface is +1 , both in form of a $\mathrm{Cu}(\mathrm{I}) \mathrm{BTA}$ and copper in a chloridic environment. For $\mathrm{pH} 4$, the signal related to $\mathrm{Cu}$ (II) seems more persistent. Changes in oxidation states for the $\mathrm{Cu}-\mathrm{BTA}$ compound were previously observed for $\mathrm{Cu}_{2} \mathrm{O}$ surfaces initially covered in a $\mathrm{Cu}^{+}-$ BTA surface compound which was gradually oxidized to a $\mathrm{Cu}^{2+}$-BTA surface compound at increased immersion times in BTA containing solutions [16]. A similar behaviour was recorded for copper-nickel alloys exposed to BTA, where the $\mathrm{Cu}$ (I)BTA film was found to rapidly oxidise to $\mathrm{Cu}$ (II)BTA upon removal form the solution [17]. However, in these cases, a change in oxidation state from +1 to +2 was observed. A further explanation for the appearance of some $\mathrm{Cu}(\mathrm{II})$ will be discussed later. In the present case other than a change in oxidation state, a decrease in the total copper signal and in particular of the component related to $\mathrm{Cu}$ (II) was detected. Moreover, the N 1s peak area is seen to decrease following a similar trend. This is probably due to the presence of a capping layer forming after the successive exposures to the BTAH solutions, rather than due to a change in oxidation state. In fact, the decrease in area of the $\mathrm{Cu} 2 \mathrm{p}_{3 / 2}$ and N $1 \mathrm{~s}$ peaks correlates with a relative increase of the $\mathrm{O} 1 \mathrm{~s}$ and $\mathrm{C} 1 \mathrm{~s}$ peak areas. This may indicate the possible growth of an adventitious contamination layer due to the adsorption of molecules from the atmosphere occurring while the samples are removed from the solutions, dried under a $\mathrm{N}_{2}$ flow and brought into the vacuum chamber for XPS analysis. A schematic illustration of the adsorption mechanism is shown in figure 5. 


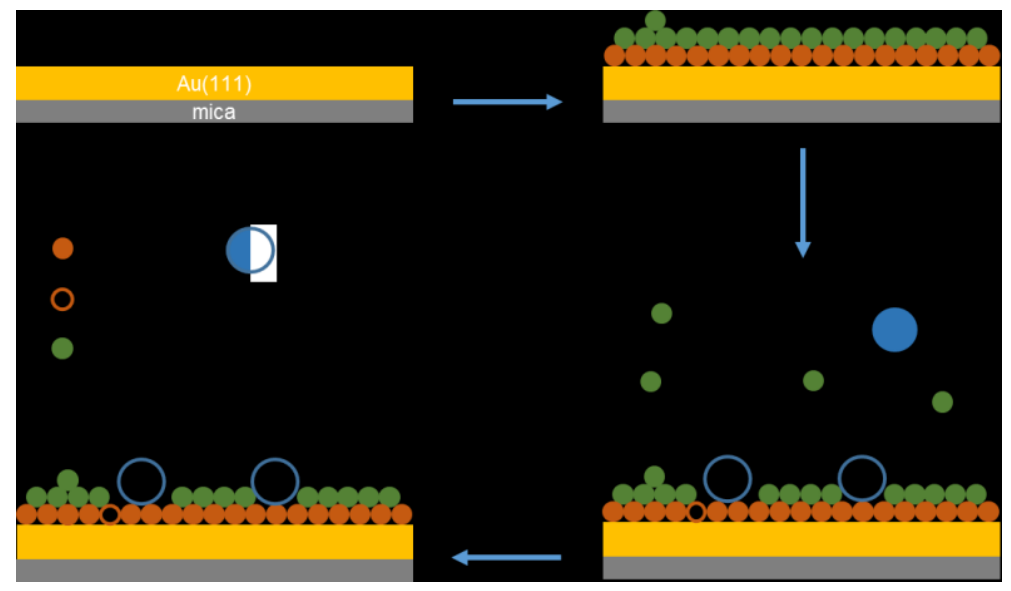

Figure 5. Schematic illustration of BTAH adsorption mechanism on a $(5 \times 5) \mathrm{Cl}$-terminated $(1 \times 1) \mathrm{Cu}(\mathrm{UPD}) / \mathrm{Au}(111) / \mathrm{mica}$ sample.

The most important difference, noted upon exposing the substrates to BTAH solutions at different $\mathrm{pH}$ after the initial immersion, is the variation in the relative intensities of the peaks comprising the copper LMM Auger transition, due to $\mathrm{Cu}-\mathrm{BTA}(915.2 \mathrm{eV})$ and copper in a chloridic environment $(917.8 \mathrm{eV})$, as reported in figure 6 a for ease of comparison.
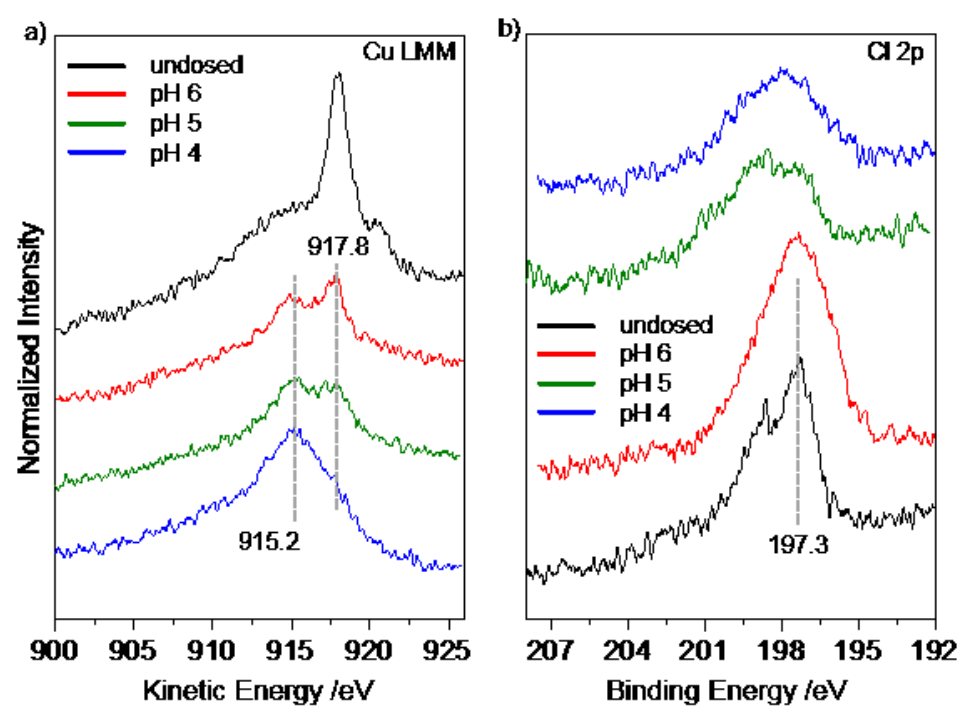

Figure 6. a) $\mathrm{Cu}$ LMM Auger transitions and b) $\mathrm{Cl} 2 \mathrm{p}$ regions before and after $30 \mathrm{~min}$ exposure to BTAH solutions at different $\mathrm{pH}$.

A peak fitting done according to the method proposed by Finšgar and co-workers [64], shows that the peak related to the $\mathrm{Cu}$-BTA species integrates roughly the same amount at $\mathrm{pH} 6$ and 5 , whereas increases significantly at $\mathrm{pH} 4$, indicating that the $\mathrm{Cu}(\mathrm{I}) \mathrm{BTA}$ surface complex forms more favourably in the more acidic environment (the peak fitting is reported in SI7). Incidentally, Cohen and co-workers reported the formation of thicker Cu-BTA overlayers on samples treated at more acidic $\mathrm{pH}$ [63]. The changes in the 
copper LMM regions are accompanied by a broadening of the $\mathrm{Cl} 2 \mathrm{p}_{3 / 2}$ region (figure $6 \mathrm{~b}$ ), which indicates the presence of additional environments for the chlorine atoms, albeit negatively charged.

The peak related to copper in a chloridic environment decreases with the increased acidity of the solution. This observation prompts a consideration on how the relative stabilities of copper and BTAH vary with $\mathrm{pH}$. Although copper does not react with hydrochloric acid, because the reduction potential of copper is higher than that of hydrogen, copper specimens immersed in $0.5 \mathrm{M} \mathrm{HCl}$ solution $[66,67,68]$ exhibit some weight loss, which is ascribed to acidic corrosion. Bulk copper is reported to go in solution as the soluble chloride complex $\mathrm{CuCl}_{2}{ }^{-}$, through a series of surface reactions involving $\mathrm{CuCl}$, which has a poor adhesion to metallic copper and hence is easily transferred to the solution $[66,67,68]$. Potential-pH diagrams report that in aqueous solution the stability of $\mathrm{CuBTA}$ and $\mathrm{CuCl}_{2}{ }^{-}$show an inverse relationship for $4<\mathrm{pH}<6$; at 0 volts, for a $10^{-2}$ total activity of dissolved BTAH species in $1 \mathrm{M} \mathrm{NaCl}$, CuBTA is the more stable species at higher $\mathrm{pH}$ values, whereas the water soluble $\mathrm{CuCl}_{2}{ }^{-}$species is more stable at $\mathrm{pH}<4$ [69]. Moreover, also the solution chemistry of $\mathrm{CuCl}$ is $\mathrm{pH}$ sensitive [70]: copper(I) chloride goes in solution as a $\mathrm{H}_{\mathrm{x}} \mathrm{CuCl}_{1+\mathrm{x}}(\mathrm{x}=1,2)$ complex for $\mathrm{pH}<2.5$. At $2.5<\mathrm{pH}<5, \mathrm{CuCl}$ disproportionates in $\mathrm{CuCl}_{2}+\mathrm{Cu}$. At $\mathrm{pH}>5.0$ copper(I) chloride undergoes alkaline hydrolysis.

In our experimental framework the acidity of the solution was kept at $4<\mathrm{pH}<6$; therefore, assuming that the reactivity of the $(5 \times 5) \mathrm{Cl}$ capped $\mathrm{Cu}(1 \times 1) / \mathrm{Au}(111) /$ mica system has some similarities with the solution chemistry of bulk $\mathrm{CuCl}$, at the operation conditions, there would be a potential for the $\mathrm{Cl}$-capped $\mathrm{Cu}$ layer to disproportionate at lower $\mathrm{pH}$ or to dissolve into solution at higher $\mathrm{pH}$. However, the UPD layer is reported as stable from neutrality to $\mathrm{pH} 1$ [42]. Nevertheless, after 30 minutes of immersion in the BTAH solutions, with decreasing $\mathrm{pH}$ a decreasing amount of copper in a chloridic environment is revealed by measurements in the $\mathrm{Cu} \mathrm{LMM}$ Auger region.

BTAH has a $\mathrm{p} K_{a}$ of 8.4 at $25^{\circ} \mathrm{C}$ in water $[5,27,69,71,72]$, which means that at $\mathrm{pH}$ values lower than $\mathrm{p} K_{a}$ the prevalent species is BTAH in its neutral form; at $\mathrm{pH}<1$ is in the protonated form, $\mathrm{BTAH}_{2}^{+}$; above 8.4 is in the anionic form, $\mathrm{BTA}^{-}$, instead. Therefore at our experimental conditions BTAH is prevalent as a solvated neutral species. UHV experiments demonstrated that BTAH can adsorb rather strongly on clean $[14,15,23$, $24,25]$ and oxidised copper surfaces [14, 15], as an anionic species. Kokalji and co-workers calculated that at the metal/vacuum interface (representative of experiments undertaken in UHV conditions), chlorine adsorbs stronger than $\mathrm{BTAH}$ on $\mathrm{Cu}(111)$, whereas the opposite should happen for the metal/water interface, because the chloride ion is much smaller and solvates much stronger in water than BTA' [73]. Because of the $\mathrm{p} K_{a}$ value, deprotonation in a solution with $4<\mathrm{pH}<6$ is likely to be a copper assisted phenomenon. Hence adsorption of BTAH on copper, in the form of BTA', has to occur through displacement of chlorine atoms, and likely surface defects act as sites for the initiation of the reaction, as a defect-free $\mathrm{Cl}-\mathrm{Cu}-\mathrm{Au} / \mathrm{mica}$ system is otherwise stable [42]. In our specific reaction environment, chlorine atoms may have some inherent degree of mobility, as it has been reported that their migration may be somehow linked with the formation of the BTA protective layer, which acts as a surface passivator for copper [27, 74, 75]. Moreover, two different factors have to be considered upon BTAH adsorption: on the one hand a chemical displacement of the 
chloride atoms, which go in solution, due to the adsorption of benzotriazole on the copper; on the other hand, after adsorption, the steric hindrance of adsorbed BTAH, BTA, may induce a physical shift of the chloride atoms, creating local accumulation of negative charge, to which the surface copper atoms will respond with local accumulation of positive charge. This may result in areas on the surface with a stoichiometry described as $\mathrm{CuCl}_{\mathrm{x}}$, with $\mathrm{x}>1$, to which a more oxidised copper signal is attributed. This generates on the XP signal a $\mathrm{Cu} 2 \mathrm{p}_{3 / 2}$ component at higher binding energy than for $\mathrm{Cu}(\mathrm{I})$ and a broadening of the $\mathrm{Cl} 2 \mathrm{p}$ peak.

The Auger features (figure 6a) seem to indicate that BTA-Cu is less sensitive than copper in a chloridic environment to the variation of $\mathrm{pH}$ : after 30 minutes of immersion, the amount of BTA-Cu is approx. the same, whereas the amount of copper in a chloridic environment species decreases with the $\mathrm{pH}$. The FWHM of the $\mathrm{Cu} \mathrm{LMM}$ Auger feature slightly increases after immersion in the solution at $\mathrm{pH} 4$, indicating the possibility of an increased amount of different chemical environments for the BTA-Cu species. As in NaCl 1 molar solution $\mathrm{CuCl}_{2}^{-}$is favoured as the $\mathrm{pH}$ decreases [69], it is conceivable to think that some of the initial $\mathrm{Cl}$-capped-Cu may go in solution more easily at lower $\mathrm{pH}$ values. Some changes in the $\mathrm{Cl} 2 \mathrm{p}$ peak point towards the chlorine related to copper in a chloridic environment peak decreasing faster than the tail, which is related to the oxychloride species. Bulk copper(II) oxychloride, $\mathrm{Cu}_{2} \mathrm{Cl}(\mathrm{OH})_{3}$, is rather insoluble in water [76], so one may think that if a surface ensamble/compund the like forms, than it probably remains adsorbed more persistently than the chloride ions, related to copper in a chloridic environment, which will be displaced preferentially. The presence of some oxychloride-like specise may be a further explanation of the presence of some $\mathrm{Cu}(\mathrm{II})$.

In general, for subsequent immersions in the same solution, the XPS signals vary in a similar way with increasing immersion times. The $\mathrm{Cu} 2 \mathrm{p}_{3 / 2}$ signal changes shape, as previously described, and decreases, whilst the $\mathrm{N} 1 \mathrm{~s}$ increases after the first measurement, as BTAH adsorbs, and then decreases. The $\mathrm{Cl} 2 \mathrm{p}$ decreases, the $\mathrm{C} 1 \mathrm{~s}$ increases dramatically after the first immersion, then stays approx. constant, the $\mathrm{O} 1 \mathrm{~s}$ generally increases. The peak shapes do not change drastically after the first immersion, indicating that the chemistry of the system is $\mathrm{pH}$ dependent rather than exposure dependent. In particular, formation of a full BTA-Cu layer does not seem to occur, as will be elucidated later.

A further insight into the copper oxidation state is offered by evaluating the modified Auger parameter, $\alpha^{\prime}$ [46], defined as the sum of the binding energy of the most intense $\mathrm{Cu} 2 \mathrm{p}_{3 / 2}$ photoelectron line and the kinetic energy of the most intense Cu LMM Auger line, for each of the preparations. The respective peak positions were read on the raw spectra and the results are summarised in Table 2. After preparation of the Cl-capped $\mathrm{Cu}$ layer, an $\alpha^{\prime}$ parameter of $1849.7 \mathrm{eV}$ is calculated. When comparing with the values reported in Table 1 , this is closer to $\alpha^{\prime}$ of bulk $\mathrm{CuCl}_{2}$, however the shape of both $\mathrm{Cu} 2 \mathrm{p}_{3 / 2}$ and $\mathrm{LMM}$ clearly indicate that the most prevalent copper oxidation state is +1 . Although $\alpha$ ' parameters evaluated for the samples immersed in the BTAH solutions at $\mathrm{pH} 6$ and $\mathrm{pH} 5$ are all consistent with copper being in +2 oxidation state, the shape of the $\mathrm{Cu} 2 \mathrm{p}_{3 / 2}$ shows that only a small amount of $\mathrm{Cu}(\mathrm{II})$ is present, with the majority still being in favour of $\mathrm{Cu}(\mathrm{I})$. The discrepancy is likely due to the fact that the values calculated in the present work, regarded as thin film surface species, are compared with valued obtained for bulk compounds. In fact the morphology of the 
adsorbate has been shown to give unexpected shifts in the Auger lines [77]. Therefore, not only the energies of the photoelectron and Auger lines, but also their shapes have to be taken into account. The $\alpha$ ' parameters evaluated for $\mathrm{pH} 4$ are more indicative of the presence of $\mathrm{Cu}(\mathrm{I})$ instead, highlighting the different behaviour in the more acidic solution.

\begin{tabular}{ccccc}
\hline \multicolumn{2}{c}{ preparation } & $\begin{array}{c}\mathrm{Cu} 2 \mathrm{p}_{3 / 2} \\
\mathrm{BE} / \mathrm{eV}\end{array}$ & $\begin{array}{c}\mathrm{Cu} \mathrm{LMM} \\
\mathrm{KE} / \mathrm{eV}\end{array}$ & $\begin{array}{c}\alpha \\
/ \mathrm{eV}\end{array}$ \\
\hline \multirow{2}{*}{$\mathrm{pH} 6$} & UPD & 932.3 & 917.4 & 1849.7 \\
& $30 \mathrm{~min}$ & 932.3 & 917.3 & 1849.6 \\
& $75 \mathrm{~min}$ & 931.9 & 917.6 & 1849.5 \\
& $120 \mathrm{~min}$ & 931.8 & 918.0 & 1849.8 \\
\hline $\mathrm{pH} 5$ & $30 \mathrm{~min}$ & 932.7 & 917.8 & 1850.5 \\
& $75 \mathrm{~min}$ & 932.8 & 917.8 & 1850.6 \\
& $120 \mathrm{~min}$ & 932.7 & 917.8 & 1850.5 \\
\hline $\mathrm{pH} 4$ & $30 \mathrm{~min}$ & 932.9 & 915.2 & 1848.1 \\
& $75 \mathrm{~min}$ & 932.7 & 915.7 & 1848.4 \\
& $120 \mathrm{~min}$ & 932.8 & 914.7 & 1847.5 \\
\hline
\end{tabular}

Table 2. $\mathrm{Cu} 2 \mathrm{p}_{3 / 2}$ binding energy, $\mathrm{Cu}$ LMM kinetic energy and modified Auger parameter values evaluated from the raw spectra.

STM images show that the layers prepared by immersion at different $\mathrm{pH}$ exhibit very similar topographical features. Benzotriazole adsorbed species are imaged as elliptical shapes with an average separation of $0.35 \pm$ $0.02 \mathrm{~nm}$, a value which well-agrees with the average spacing of a chloride terminated overlayer with a $(5 \times 5)$ geometry, over a $\mathrm{Cu}(1 \times 1)$ layer, commensurate with the underlying $\mathrm{Au}(111)$ [42]. Adsorption has to occur by displacement of the chlorine atoms and may be favoured in solution because chloride is solvated by water more effectively than BTAH [73]. Molecular features are seen to propagate in three directions rotated by $120^{\circ}$ with respect to each other. Molecular ensembles, however, do not have a regular width and don't propagate in a straight line. Adsorption of an upright $\mathrm{Cu}(\mathrm{I})$-BTA compound in bidentate configuration, whereby each deprotonated BTAH molecule coordinates with two copper atoms through either the $\mathrm{N}_{1}$ and $\mathrm{N}_{2}$ nitrogen atoms, or the equivalent $\mathrm{N}_{2}$ and $\mathrm{N}_{3}$, can explain the variations seen. In fact, even though chemically indistinguishable, adsorption through one of the two couples will result in a molecule tilting in the opposite direction as if adsorption were to occur through the other. Considering two molecules adsorbed upright and with the planes containing the aromatic systems parallel to each other, successive adsorption through $\mathrm{N}_{1}$ and $\mathrm{N}_{2}$ (or the equivalent $\mathrm{N}_{2}$ and $\mathrm{N}_{3}$ ) will result in a geometry which may favour the superposition of the $\pi$ systems leading to a $\pi$ - $\pi$ interaction. However, the alternation of a molecule adsorbed through $N_{1}$ and $N_{2}$ with one adsorbed through $\mathrm{N}_{2}$ and $\mathrm{N}_{3}$ will result in a geometry not compatible with a $\pi-\pi$ superposition. It has been reported that, in general, in a $\pi-\pi$ interaction, aromatic rings are parallel displaced in an offset or slipped stacking configuration more often than not [47]. Such parallel-displaced structures are also thought to have a contribution from a $\sigma-\pi$ interaction, the more favourable with increasing offset. If this were the case, a chain 
with regular width would be expected. The balance between $\sigma-\pi$ and $\pi-\pi[78,79]$ and surface - molecule interactions has been reported to have an effect at much larger range than that observed in the present study. For example, they have been shown to produce unexpected 2D structures, like supramolecular corrals, on which the closest separation between the observed features is calculated as $3.2 \AA$ for dimer pairs [80], and 3D Kagome-like lattices, where $\pi-\pi$ stacked molecular dimers adsorb perpendicularly over a layer of flatlying molecules [81].

Perhaps a further factor which can have an effect in the molecular orientation is due to the varying spacing of the $(5 \times 5)$ chloride layer, i.e. when molecules would be too close to each other an offset configuration would be preferred. The featureless areas on the STM images are occupied by the chlorine atoms, which are not resolved at these specific scanning conditions.

With increasing exposure, STM images shows a small increase in surface coverage, however XPS seems to show a decrease of the copper, chlorine and nitrogen signals, accompanied by an increase of the carbon and oxygen ones. Because adsorption phenomena normally occur on a much quicker timescale than our first measurement (i.e. 30 minutes of immersion time), our results are more representative of an equilibrium state between molecules adsorbing on the surface and going back into solution. The increase in coverage evaluated from both XPS measurements and STM images is not linear, suggesting that when some adsorption sites are occupied by BTAH, some adjacent sites may be destabilised, therefore further adsorption is rendered more difficult. Such destabilisation effects could be electronic, because the remaining chloride ions may be more difficult to displace from potential adsorption sites, because they more strongly bound, or physical, because the presence of BTAH molecules hinders further BTAH from adsorbing. The competiveness of adsorption between BTAH and chlorine may account for the observation of short molecular ensembles, which grow very slowly with prolonged immersion times. The increased number of chemical species present in the system, copper in a chloridic environment, Cu-BTA, adventitious contaminants, renders extremely difficult to establish a precise $\mathrm{Cu}$ :BTA stoichiometry via XPS. However, on the basis of the STM images, as molecules are through to adsorb upright, a Cu:BTA $\approx 2: 1$ stoichiometry would correspond to a bidentate adsorption (through $\mathrm{N}_{1}$ and $\mathrm{N}_{2}$, or equivalent $\mathrm{N}_{2}$ and $\mathrm{N}_{3}$ ). A Cu:BTA $\approx 1: 1$ stoichiometry would be expected for monodentate adsorption (through the $\mathrm{N}_{1}\left(\mathrm{~N}_{3}\right)$ or $\mathrm{N}_{2}$ atom) instead. Computational studies report that for neutral BTAH, "bridge-N2+N3" adsorption is slightly more favourable than "top-N3" and "top-N2", whereas bidentate adsorption is strongly favoured for dehydrogenated BTA $\odot$ $[33,34,73,82]$.

Previous STM studies have proposed that on $\mathrm{Cu}(100)$ in a $\mathrm{H}_{2} \mathrm{SO}_{4}$ electrochemical environment, depending on the potential employed, benzotriazole can adsorb in different configurations: an ordered phase of flat lying molecules and disordered chains with a spacing of $0.42 \mathrm{~nm}$, compatible with the $4.13 \AA$ lattice spacing along the $c$-axis of crystalline BTA, along which the molecules are oriented almost parallel to each other [19]. This suggests a parallel upright stacking of BTA molecules for the disordered chains, adsorbed through the nitrogen lone pairs [19]. On $\mathrm{Cu}(111)$, a poorly ordered adlayer phase containing individual BTAH chains with a interspacing of approximately $4 \mathrm{~nm}$ along the chain, orientated upright with respect to the surface was 
observed [20]. In a $\mathrm{H}_{2} \mathrm{SO}_{4}$ electrochemical environment, the observation that $\mathrm{BTAH}$ formed more ordered adlayers, for a wider range of potentials, on $\mathrm{Cu}(100)$ than on $\mathrm{Cu}(111)$ was linked to the increased resistance of the (100) BTA coverd surface towards the adsorption of chloried ions [83]. In a hydrochloric acid environment, BTAH was seen to adsorb with its molecular plane upright or slightly tilted in a double row structure [21]. Also in a $\mathrm{HClO}_{4}$ environment, BTAH molecules were found to adopt an upright adsorption geometry and being stacked into straight molecular rows on $\mathrm{Cu}(111)$, whereas on $\mathrm{Cu}(110)$ and $\mathrm{Cu}(100)$ a flat-lying orientation was detected [84].

Under UHV conditions on $\mathrm{Cu}(111)$, BTAH was found to adsorb predominantly as a $\mathrm{Cu}(\mathrm{BTA})_{2}$ dimer, whereas some monomers were also seen $[28,29]$ In the low coverage regime features widths of ca. $0.5 \mathrm{~nm}$ and ca. $1 \mathrm{~nm}$, for Cu-BTA and BTA-Cu-BTA units respectively, were reported. On oxygen free and oxygen covered $\mathrm{Cu}(110)$, BTAH was seen to adsorb forming ordered $\mathrm{c}(4 \times 2)$ domains and disordered phases respectively, with preference for adsorption on the oxygen covered areas [14, 15].

\section{Conclusions}

The behaviour of Cl-capped $\mathrm{Cu}(111)$ monolayers prepared via UPD methods on $\mathrm{Au}(111) /$ mica immersed in BTAH solutions at different $\mathrm{pH}$ was investigated via X-ray photoelectron spectroscopy (XPS) and scanning tunnelling microscopy (STM).

XPS revealed that a $\mathrm{Cu}(\mathrm{I}) \mathrm{BTA}$ surface compound is formed upon immersion in the BTAH solutions. While a small amount of copper in a +2 oxidation state is seen initially, $\mathrm{Cu}(\mathrm{I})$ is the species always prevalent. The layers appear to be chemically very similar; however, the interaction with BTAH seems more favourable at lower $\mathrm{pH}$, when $\mathrm{BTAH}$ is more effective in displacing the chlorine atoms from the copper layer. As the amount of BTAH grows very slowly with increasing exposure, this may represent an equilibrium situation in which BTAH molecules and chloride ions are coadsorbed on the copper layer and competitive.

STM measurements show that BTAH adsorbs as upright species, parallel stacked, with an intermolecular distance compatible with a $\pi-\pi$ interaction. Although a BTA-Cu metalorganic compound forms upon adsorption, this is in the form of discrete units and an extended metal-organic polymer was not identified. The observed features appeared having similar morphology, independently of $\mathrm{pH}$ and immersion time.

This study contributes to a further understanding of the interaction between benzotriazole and copper in solution, with focus on the species adsorbed on the copper, by highlighting its complexity and $\mathrm{pH}$ dependency.

\section{Acknowledgments}

A. M. acknowledges financial support from the Erasmus + for Traineeship programme of the European Union. Prof. M. Buck and R. O. de la Morena are greatly acknowledged for assistance in the preparation of the substrates and helpful advice; Prof. N. V. Richardson is thanked for fruitful discussions and suggestions. 
Supplementary material: cyclic voltammetry, fitted XP and Auger spectra, reference Auger spectra, additional STM images.

\section{Author's declaration}

All authors have approved the final version of the manuscript.

The authors declare no conflict of interest.

\section{Data availability}

The raw data required to reproduce these findings are available to download from

http://dx.doi.org/10.17630/3175f32b-2508-441f-9f3e-e86c5604f076

\section{References}

1. International Copper Study Group, The World Copper Factbook 2014, http://www.icsg.org; (accessed Septemeber 2017).

2. J. R. Myers, A. Cohen, Conditions Contributing to Underground Copper Corrosion, Journal American Water Work Association, (1984) pp 68-71.

3. British Patent 625339, Compositions for Inhibiting Metal Tarnish, 09 December 1947, P\&G Ltd.

4. M. M. Antonijevic, M. B. Petrovic, Copper corrosion inhibitors. A review, Int. J. Electrochem. Sci. 3 (2008) 1-28.

5. M. Finšgar, I. Milošev, Inhibition of copper corrosion by 1,2,3-benzotriazole: A review, Corros. Sci. 52 (2010) 2737-2749.

6. M. B. P. Mihajlović, M. M. Antonijević, Copper Corrosion Inhibitors. Period 2008-2014. A Review, Int. J. Electrochem. Sci. 10 (2015) 1027-1053.

7. I. Dugdale, J. B. Cotton, An electrochemical investigation on the prevention of staining of copper by benzotriazole, Corros. Sci. 3 (1963) 69-74.

8. J. B. Cotton, I. R. Scholes, Benzotriazole and Related Compounds as Corrosion Inhibitors For Copper, Brit. Corros. J. 2 (1967) 1-5.

9. G. W. Poling, Reflection infra-red studies of films formed by benzotriazole on $\mathrm{Cu}$, Corros. Sci. 10 (1970) 359-370.

10. B. S. Fang, C. G. Olson, D. W. Lynch, A photoemission study of benzotriazole on clean copper and cuprous oxide, Surf. Sci. 176 (1986) 476-490. 
11. R. Youda, H. Nishihara, K. Aramaki, Sers and impedance study of the equilibrium between complex formation and adsorption of benzotriazole and 4-hydroxybenzotriazole on a copper electrode in sulphate solutions, Electrochim. Acta 35 (1990) 1011-1017.

12. F. Mansfeld, T. Smith, E. P. Parry, Benzotriazole as corrosion inhibitor for copper, Corrosion 27 (1971) 289-294.

13. J. O. Nilsson, C. Tornkvist, B. Liedberg, Photoelectron and infrared reflection absorption spectroscopy of benzotriazole adsorbed and cuprous oxide surfaces, Appl. Surf. Sci. 37 (1989) 306326.

14. K. Cho, J. Kishimoto, T. Hashizume, H. W. Pickering, T. Sakurai, Adsorption and film growth of BTA on clean and oxygen adsorbed Cu(110) surfaces, Appl. Surf. Sci. 87/88 (1995) 380-385.

15. K. Cho, J. Kishimoto, T. Hashizume, H. W. Pickering, T. Sakurai, An Observation of Benzotriazole (BTA) Adsorption on $\mathrm{Cu}(110)$ by the Ultra High Vacuum (UHV)-Scanning Tunneling Microscope (STM) and Low Energy Electron Diffraction (LEED), Jpn. J. Appl. Phys. 33 (1994) L125- L128.

16. R. F. Roberts, X-Ray photoelectron spectroscopic characterization of copper oxide surfaces treated with benzotriazole, J. Electron. Spectrosc. Related Phen. 4 (1974) 273-291.

17. D. Chadwick, T. Hashemi, Adsorbed corrosion inhibitors studied by electron spectroscopy: Benzotriazole on copper and copper alloys, Corros. Sci. 18 (1978) 39-51.

18. P. G. Fox, G. Lewis, P. J. Boden, Some chemical aspects of the corrosion inhibition of copper by benztriazole, Corros. Sci. 19 (1979) 457-467.

19. M. R. Vogt, W. Polewska, O. M. Magnussen, R. J. Behm, In Situ STM Study of (100) Cu Electrodes in Sulfuric Acid Solution in the Presence of Benzotriazole, J. Electrochem. Soc. 144 (1997) L113L116.

20. W. Polewska, M. R. Vogt, O. M. Magnussen, R. J. Behm, In Situ STM Study of Cu(111) Surface Structure and Corrosion in Pure and Benzotriazole-Containing Sulfuric Acid Solution, J. Phys. Chem. B 103 (1999) 10440-10451.

21. M. R. Vogt, R. J. Nichols, O. M. Magnussen, R. J. Behm, Benzotriazole Adsorption and Inhibition of $\mathrm{Cu}(100)$ Corrosion in HCl: A Combined in Situ STM and in Situ FTIR Spectroscopy Study, J. Phys. Chem. B 102 (1998) 5859-5865.

22. A. Kokalj, S. Peljhan, M. Finšgar, I. Milošev, What Determines the Inhibition Effectiveness of ATA, BTAH, and BTAOH Corrosion Inhibitors on Copper? J. Am. Chem. Soc. 132 (2010) 16657-16668.

23. J. F. Walsh, H.S. Dhariwal, A. Gutiérrez-Sosa, P. Finetti, C. A. Muryn, N. B. Brookes, R. J. Oldman, G. Thornton, Probing molecular orientation in corrosion inhibition via a NEXAFS study of benzotriazole and related molecules on $\mathrm{Cu}(100)$, Surf. Sci. 415 (1998) 423-432.

24. F. Grillo, D.W. Tee, S.M. Francis, H. Früchtl, N.V. Richardson, Initial stages of benzotriazole adsorption on the $\mathrm{Cu}(111)$ surface, Nanoscale 5 (2013) 5269-5273.

25. F. Grillo, D. W. Tee, S. M. Francis, H. A. Früchtl, N. V. Richardson, Passivation of Copper: Benzotriazole Films on Cu(111), J. Phys. Chem. C 118 (2014) 8667-8675. 
26. G. Xue, J. Ding, P. Cheng, Growth of a surface film on copper from benzotriazole solutions, Appl. Surf. Sci. 89 (1995) 77-82.

27. D. Tromans, R. H. Sun, Anodic Polarization Behavior of Copper in Aqueous Chloride/Benzotriazole Solutions, J. Electrochem. Soc. 138 (1991) 3235-3244.

28. V. Brusic, M. A. Frisch, B. N. Eldridge, F. P. Novak, F. B. Kaufman, B. M. Rush, G. S. Frankel, Copper corrosion with and without inhibitors, J. Electrochem. Soc. 138 (1991) 2253-2259.

29. P. F. Khan,V. Shanthi, R. K. Babu, S. Muralidharan, R. C. Barik, Effect of benzotriazole on corrosion inhibition of copper under flow conditions, J. Environmental Chem. Eng. 3 (2015) 10-19.

30. X. Lü, X. Lu, J. Luo, Influence of pH, immersion time, and benzotriazole concentration on copper corrosion in citric acid based slurries., J. Chin. Sci. Bull. 56 (2011) 1158-1164.

31. P. G. Cao, J. L. Yao, J. W. Zheng, R. A. Gu, Z. Q. Tian, Comparative Study of Inhibition Effects of Benzotriazole for Metals in Neutral Solutions As Observed with Surface-Enhanced Raman Spectroscopy, Langmuir 18 (2002) 100-104.

32. C. Gattinoni, A. Michaelides, Understanding corrosion inhibition with van der Waals DFT methods: the case of benzotriazole, Faraday Discuss. 180 (2015) 439-458.

33. A. Kokalj, S. Peljhan, Density Functional Theory Study of ATA, BTAH, and BTAOH as Copper Corrosion Inhibitors: Adsorption onto $\mathrm{Cu}(111)$ from Gas Phase, Langmuir 26 (2010) 14582-14593.

34. S. Peljhan, A. Kokalj, DFT Study of Gas-Phase Adsorption of Benzotriazole on $\mathrm{Cu}(111), \mathrm{Cu}(100)$, $\mathrm{Cu}(110)$, and low Coordinated Defects thereon, Phys. Chem. Chem. Phys. 13 (2011) 20408-20417.

35. X. Chen, H. Häkkinen, Divide and Protect: Passivating $\mathrm{Cu}(111)$ by $\mathrm{Cu}$-(benzotriazole)2, J. Phys. Chem. C 116 (2012) 22346-22349.

36. Y. Jiang, J. B. Adams, First principle calculations of benzotriazole adsorption onto clean $\mathrm{Cu}(111)$, Surf. Sci. 529 (2003) 428-442.

37. F. Grillo, J. A. Garrido Torres, M. -J. Treanor, C. R. Larrea, J. P. Gotze, P. Lacovig, H. A. Früchtl, R. Schaub, N. V. Richardson, Two-dimensional self-assembly of benzotriazole on an inert substrate, Nanoscale 8 (2016) 9167-9177.

38. S. Neodo, D. Carugo, J.A. Wharton, K. R. Stokes, Electrochemical behaviour of nickel-aluminium bronze in chloride media: Influence of pH and benzotriazole, J. Electroanalytical Chem. 695 (2013) $38-46$.

39. G. Trabanelli, A. Frignani, C. Monticelli, F. Zucchi, Alkyl-benzotriazole derivatives as inhibitors of iron and copper corrosion, Int. J. Corros. Scale Inhib. 4 (2015) 96-107.

40. J. Hotlos, O. M. Magnussen, R. J. Behm, Effect of trace amounts of $\mathrm{C1}^{-}$in $\mathrm{Cu}$ underpotential deposition on $\mathrm{Au}(111)$ in perchlorate solutions: an in-situ scanning tunneling microscopy study, Surf. Sci. 335 (1995) 129-144.

41. M. A. Schneeweiss, D. M. Kolb, The Initial Stages of Copper Deposition on Bare and Chemically Modified Gold Electrodes, Phys. Stat. Sol. A 173 (1999) 51-71. 
42. H. Aitchison, N. Meyerbröker, T. -L. Lee, J. Zegenhagen, T. Potter, H. A. Früchtl, I. Cebula, M. Buck, Underpotential Deposition of $\mathrm{Cu}$ on $\mathrm{Au}(111)$ from Neutral Chloride Containing Electrolyte, PhysChemChemPhys 19 (2017) 24146-24153.

43. CasaXPS software version 2.3.17 (Casa Software Ltd, Teignmouth, UK)

44. I. Horcas R. Fernández, J. M. Gómez-Rodríguez, J. Colchero, J. Gómez-Herrero, A. M. Baro, WSXM: A Software for Scanning Probe Microscopy and a Tool for Nanotechnology, Rev. Sci. Instrum. 78 (2007) 013705.

45. N. Pauly, S.Tougaard, F.Yubero, LMM Auger primary excitation spectra of copper, Surf. Sci. 630 (2014) 294-299.

46. X-ray Photoelectron Spectroscopy DatabaseVersion 4.1 (National Institute of Standards and Technology, Gaithersburg, 2012) http://srdata.nist.gov/xps/ (accessed January 2018).

47. C. Janiak, A critical account on $\pi-\pi$ stacking in metal complexes with aromatic nitrogen-containing ligands, J. Chem. Soc. Dalton Trans. (2000) 3885-3896.

48. O. Cavalleri, A. M. Bittner, H. Kind, K. Kern, Copper Electrodeposition on Alkanethioleate Covered Gold Electrodes, Zeitschrift für Physikalische Chemie. Bd. 208 (1999) 107-136.

49. F. P. Zamborini, J. K. Campbell, R. M. Crooks, Spectroscopic, Voltammetric, and Electrochemical Scanning Tunneling Microscopic Study of Underpotentially Deposited Cu Corrosion and Passivation with Self-Assembled Organomercaptan Monolayers, Langmuir 14 (1998) 640-647.

50. G. Van der Laan, G. A. Sawatzky, C. Haas, Photoelectron and Auger Spectroscopy of CuCl, Phys. Rev. B 20 (1979) 4287-4293.

51. G. Van Der Laan, C. Westra, C. Haas, G. A. Sawatzky, Satellite structure in photoelectron and Auger spectra of copper dihalides, Phys. Rev. B 23 (1981) 4369-4380.

52. J. C. Klein, A. Proctor, D. M. Hercules, J. F. Black, X-ray excited Auger intensity ratios for differentiating copper compounds, Anal. Chem. 55 (1983) 2055-2059.

53. J. C. Klein, C. P. Li, D. M. Hercules, J. F. Black, Decomposition of Copper Compounds in X-Ray Photoelectron Spectrometers, Appl. Spectrosc. 38 (1984) 729-723.

54. C. Battistoni, G. Mattongno, E. Paparazzo, L. Naldini, An XPS and Auger study of some polynuclear copper compounds, Inorg. Chim. Acta 102 (1985) 1-3.

55. D. Tahir, S. Tougaard, Electronic and optical properties of $\mathrm{Cu}, \mathrm{CuO}$ and $\mathrm{Cu}_{2} \mathrm{O}$ studied by electron spectroscopy, J. Phys.: Condens. Matter 24 (2012) 175002.

56. J. P. Tobin, W. Hirschwald, J. Cunningham, XPS and XAES studies of transient enhancement of $\mathrm{Cu}^{\mathrm{I}}$ at $\mathrm{CuO}$ surfaces during vacuum outgassing, Application Surf. Sci. 16 (1983) 441-452.

57. S. Poulston, P. M. Parlett, P. Stone, M. Bowker, Surface Oxidation and Reduction of $\mathrm{CuO}$ and $\mathrm{Cu}_{2} \mathrm{O}$ Studied Using XPS and XAES, Surf. Interf. Analysis 24 (1996) 811-820.

58. D. Barreca, A, Gasparotto, E. Tondello, $\mathrm{CVD} \mathrm{Cu}_{2} \mathrm{O}$ and $\mathrm{CuO}$ Nanosystems Characterized by XPS, Surf. Sci. Spectra 14 (2007) 41-51. 
59. D. Chadwick, T Hashemi, Benzotriazole adsorption on copper studied by X-ray photoelectron spectroscopy, J. Electron Spectrosc. Relat. Phenom. 10 (1977) 79-83.

60. K. Mansikkamäki, U. Haapanen, C. Johans, K. Kontturi, M. Valden, Adsorption of Benzotriazole on the Surface of Copper Alloys Studied by SECM and XPS, J. Electrochem. Soc. 153 (2006) B311B318.

61. Practical Surface Analysis, $2^{\text {nd }}$ Ed.; D. Briggs, M. P. Seah, Eds.; John Wiley \& Sons: New York, 1990; Vol. 1, pp 487-529.

62. C. D. Wagner, W. M. Kiggs, L. E. Davis, J. F. Moulder, Handbook of X-ray Photoelectron Spectroscopy; Perkin-Elmer Corporation-Physical Electronics Division: Eden Prairie, MN, 1979.

63. S. L. Cohen, V. A. Brusic, F. B. Kaufman, G. S. Frankel, S. Motakef, B. Rush, X-ray photoelectron spectroscopy and ellipsometry studies of the electrochemically controlled adsorption of benzotriazole on copper surfaces, J. Vac. Sci. \& Technology A 8 (1990) 2417-2425.

64. M. Finšgar, S. Peljhan, A. Kokalj, J. Kovač, I. Milošev, Determination of the $\mathrm{Cu}_{2} \mathrm{O}$ Thickness on BTAH-Inhibited Copper by Reconstruction of Auger Electron Spectra, J. Electrochem. Soc. 157 (2010) C295-C301.

65. M. Finšgar, J. Kovač, I. Milošev, Surface Analysis of 1-Hydroxybenzotriazole and Benzotriazole Adsorbed on Cu by X-Ray Photoelectron Spectroscopy, J. Electrochem. Soc. 157 (2010) C52-C60.

66. El-Sayed M. Sherif, R. M. Erasmus, J. D. Comins, Effects of 3-amino-1,2,4-triazole on the inhibition of copper corrosion in acidic chloride solutions, J. Coll. Interf. Sci. 311 (2007) 144-151.

67. Sudheer, M. A. Quraishi, Electrochemical and theoretical investigation of triazole derivatives on corrosion inhibition behavior of copper in hydrochloric acid medium, Corr. Sci. 70 (2013) 161-169.

68. D. -Q. Zhang, Q. -R. Cai, X. -M. He, L. -X. Gao, G. S. Kim, The corrosion inhibition of copper in hydrochloric acid solutions by a tripeptide compound, Corr. Sci. 51 (2009) 2349-2354.

69. D. Tromans, Aqueous Potential-pH Equilibria in Copper-Benzotriazole Systems, J. Electrochem. Soc. 145 (1998) L42-L45.

70. H. Liu, Y. Zhou, S. A. Kulinich, J. -J. Li, L. -L. Han, S. -Z. Qiao, X. -W. Du, Scalable synthesis of hollow $\mathrm{Cu}_{2} \mathrm{O}$ nanocubes with unique optical properties via a simple hydrolysis-based approach, $\mathrm{J}$. Mater. Chem. A 1 (2013) 302-307.

71. J. -L. Wang, C. Ke, K. Pohl, N. Birbilis, X. -B. Chen, The Unexpected Role of Benzotriazole in Mitigating Magnesium Alloy Corrosion: A Nucleating Agent for Crystalline Nanostructured Magnesium Hydroxide Film, J. Electrochem. Soc. 162 (2015) C403-C411.

72. L. D. Hansen, B. D. West, E. J. Baca, C. L. Blank, Thermodynamics of Proton Inonizaion from Some Substituted 1,2,3-Triazoles in Diluite Aqueous Solution, J. Am. Chem. Soc. 90 (1968) 65886592.

73. S. Peljhan, J. Koller, A. Kokalj, The Effect of Surface Geometry of Copper on Adsorption of Benzotriazole and Cl. Part I, J. Phys. Chem C 118 (2014) 933-943. 
74. U. R. Evans The Corrosion and Oxidation of Metals, First Supplementary Volume, St. Martin's Press, New York (1968).

75. A. D. Modestov, G. -D. Zhou, Y. -P. Wu, T. Noyota, D. P. Schweinsberg, A study of the electrochemical formation of $\mathrm{Cu}(\mathrm{I})$-BTA films on copper electrodes and the mechanism of copper corrosion inhibition in aqueous chloride/benzotriazole solutions, Corr. Sci. 36 (1994) 1931-1946.

76. A. Lubej, T. Koloini, C. Pohar, Solubility of Copper(2) Oxychloride, Ind. Eng. Chem. Res. 36 (1997) 241-245.

77. J. P. Espinós, J. Morales, A. Barranco, A. Caballero, J. P. Holgado, A. R. González-Elipe, Interface Effects for $\mathrm{Cu}, \mathrm{CuO}$, and $\mathrm{Cu}_{2} \mathrm{O}$ Deposited on $\mathrm{SiO}_{2}$ and $\mathrm{ZrO}_{2}$. XPS Determination of the Valence State of Copper in $\mathrm{Cu} / \mathrm{SiO}_{2}$ and $\mathrm{Cu} / \mathrm{ZrO}_{2}$ Catalysts, J. Phys. Chem. B 106 (2002) 6921-6929.

78. C. A. Hunter, J. K. Sanders, The Nature of $\pi-\pi$ Interactions. J. Am. Chem. Soc. 112 (1990) 55255534.

79. C. R. Martinez, B. L. Iverson, Rethinking the term "pi-stacking" Chem. Sci. 3 (2012) 2191-2201.

80. S. J. Jethwa, E. L. Kolsbjerg, S. R. Vadapoo, J. L. Cramer, L. Lammich, K. V. Gothelf, B. Hammer, T. R. Linderoth, Supramolecular Corrals on Surfaces Resulting from Aromatic Interactions of Nonplanar Triazoles, ACSNano 11 (2017) 8302-8310.

81. S. Beniwal, S. Chen, D. A. Kunkel, J. Hooper, S. Simpson, E. Zurek, X. C. Zeng, A. Enders, Kagome-like Lattice of $\pi$ - $\pi$ stacked 3-hydroxyphenalenone on $\mathrm{Cu}(111)$. Chem. Commun. 50 (2014) 8659-8662.

82. A. Kokalj, S. Peljhan, J. Koller, The Effect of Surface Geometry of Copper on Dehydrogenation of Benzotriazole. Part II, J. Phys. Chem C 118 (2014) 944-954.

83. Z. D. Schultz, M. E. Biggin, J. O. White, A. A. Gewirth, Infrared-Visible Sum Frequency Generation Investigation of $\mathrm{Cu}$ Corrosion Inhibition with Benzotriazole, Anal. Chem. 76 (2004) 604-609.

84. M. Sugimasa, L. -J. Wan, J. Inukai, K. Itaya, Adlayers of Benzotriazole on $\mathrm{Cu}(110)$, (100), and (111) in $\mathrm{HClO}_{4}$ Solution In Situ Scanning Tunneling Microscopy Study, J. Electrochem. Soc. 149 (2002) E367-E373. 